\section{SARS-CoV-2 Exposure in Escaped Mink, Utah, USA}

Susan A. Shriner, Jeremy W. Ellis, J. Jeffrey Root, Annette Roug, Scott R. Stopak, Gerald W. Wiscomb, Jared R. Zierenberg, Hon S. Ip, ${ }^{1}$ Mia K. Torchetti, ${ }^{1}$ Thomas J. DeLiberto ${ }^{1}$

Author affiliations: US Department of Agriculture (USDA)
National Wildlife Research Center, Fort Collins, Colorado, USA

(S.A. Shriner, J.W. Ellis, J.J. Root, T.J. DeLiberto); Utah Division of Wildlife Resources, Salt Lake City, Utah, USA (A. Roug); USDA Wildlife Services, Boise, Idaho, USA (S.R. Stopak); USDA Wildlife Services, Billings, Montana, USA (G.W. Wiscomb); USDA Wildlife Services, Salt Lake City (J.R. Zierenberg); US Geological Survey National Wildlife Health Center, Madison, Wisconsin, USA (H.S. Ip); USDA Veterinary Services, Ames, lowa, USA (M.K. Torchetti)

DOI: https://doi.org/10.3201/eid2703.204444

In August 2020, outbreaks of coronavirus disease were confirmed on mink farms in Utah, USA. We surveyed mammals captured on and around farms for evidence of infection or exposure. Free-ranging mink, presumed domestic escapees, exhibited high antibody titers, suggesting a potential severe acute respiratory syndrome coronavirus 2 transmission pathway to native wildlife.

$\mathrm{W}^{2}$ e report a wildlife epidemiologic investigation of mammals captured on or near properties in Utah, USA, where outbreaks of severe acute respiratory syndrome coronavirus 2 (SARS-CoV-2) infection occurred in farmed mink. Mink farms are relatively common in the United States, and most are small family farms. The US Department of Agriculture's National Veterinary Services Laboratories (Ames, IA, USA) confirmed SARS-CoV-2 in mink at 2 Utah farms on August 17, 2020, after an investigation by the Utah Veterinary Diagnostic Laboratory and the Washington Animal Disease Diagnostic Laboratory (1). SARS-CoV-2 outbreaks have subsequently been confirmed at multiple farms in Utah, Michigan, Wisconsin, and Oregon. Although epidemiologic investigations are ongoing, infected workers are the probable source of the virus's introduction (2).

The first reported SARS-CoV-2 infection in mink occurred in the Netherlands in April 2020 (3). Since then, dozens of farms in Europe have experienced outbreaks, and more than a million mink have been culled (2). Genetic analyses suggest spillover from human infections, and potential zoonotic transmission

${ }^{1}$ These senior authors contributed equally to this article. from mink to a worker is suspected (4). Clinical data from mink infected with SARS-CoV-2 indicate the species is highly susceptible and that infections can range from asymptomatic to peracute (5).

We captured free-roaming mammals during August 22-30, 2020, by using Sherman (rodents) and Tomahawk (mesocarnivores) traps placed outside of barns and barrier fences on outbreak premises and public lands within a 3.5-km buffer zone. Sample collection included oral, nasal (washes for mice), and rectal swab specimens; tissue specimens; and blood specimens. Swabs were placed in cryovials filled with $0.5 \mathrm{~mL}$ viral transport medium, and tissue specimens were placed in plastic sample bags or cryovials. Serum and swab samples were stored on ice, and tissue specimens were flash frozen on dry ice. Most samples were shipped within 24 hours. Swabs and serum samples were shipped to the National Veterinary Services Laboratories, and tissue specimens were sent to the US Geological Survey National Wildlife Health Center (Madison, WI, USA) for testing. All swabs and tissue specimens were tested for SARS-CoV-2 viral RNA by real-time reverse transcription PCR (rRT-PCR) targeting the N1 and N2 genes, and serum samples were tested by virus neutralization assay (6). A positive rRT-PCR result was defined as detection of both N1 and N2.

We captured 102 mammals (78 rodents and 24 mesocarnivores). Rodent captures consisted of 45 deer mice (Peromyscus maniculatus), 5 Peromyscus spp. mice, 25 house mice (Mus musculus), and 3 rock squirrels (Otospermophilus variegatus). Mesocarnivore captures consisted of 11 presumed escaped American mink (Neovison vison), 2 presumed wild American mink, 5 raccoons (Procyon lotor), and 6 striped skunks (Mephitis mephitis). Presumed escaped mink were closely associated with barns and designated as domestic escapees on the basis of location, behavior, and appearance. We identified wild mink by brown coat color and smaller size compared with farmed mink. All escaped mink and rodents, except for 4 deer mice and 1 rock squirrel, were caught on farm premises. All raccoons, the 2 presumed wild mink, and all but 1 striped skunk were captured off-property but within the buffer zone.

Serum samples from the 11 mink escapees tested positive for SARS-CoV-2 antibodies by virus neutralization (Table). No other animal had a detectable antibody response. Of the antibody-positive escaped mink, 3 also had high cycle threshold $\left(C_{t}\right)$ detections by rRT-PCR of nasal swabs (range $C_{t}$ 35.89-38.95) and 1 lung tissue specimen $\left(C_{t} 39.2\right.$ for N1). A rectal swab specimen from a house mouse had a high $C_{t}$ detection by rRT-PCR but was negative for SARS-CoV-2 antibodies. N1 alone was 
Table. Virus neutralization titers and rRT-PCR cycle thresholds for samples collected from captured mammals in study of SARS-CoV2 exposure in escaped mink, Utah, USA, August 2020

\begin{tabular}{|c|c|c|c|c|c|c|}
\hline Animal ID & Animal & Capture date & Site & Virus neutralization titer & rRT-PCR $C_{t} \dagger$ & rRT-PCR sample type \\
\hline ID000003 & Escaped mink & 2020 Aug 23 & A & 128 & ND & ND \\
\hline ID000004 & Escaped mink & 2020 Aug 23 & A & 128 & ND & ND \\
\hline ID000101 & Escaped mink & 2020 Aug 24 & A & 512 & ND & ND \\
\hline ID000010 & Escaped mink & 2020 Aug 24 & A & 512 & 38.80 & Nasal swab \\
\hline ID000011 & Escaped mink & 2020 Aug 24 & $A$ & 512 & ND & ND \\
\hline ID000012 & Escaped mink & 2020 Aug 24 & A & 512 & 38.95 & Nasal swab \\
\hline ID000013 & Escaped mink & 2020 Aug 24 & A & 128 & ND & ND \\
\hline ID000014 & Escaped mink & 2020 Aug 24 & A & 256 & $\ddagger$ & Nasal swab, lung tissue \\
\hline ID000052 & Escaped mink & 2020 Aug 30 & B & 64 & $\ddagger$ & Nasal swab \\
\hline ID000053 & Escaped mink & 2020 Aug 30 & B & 256 & 37.38 & Nasal swab \\
\hline ID000054 & Escaped mink & 2020 Aug 30 & B & 128 & ND & ND \\
\hline ID000030 & Feral or wild mink & 2020 Aug 26 & C & Negative & ND & ND \\
\hline ID000051 & Feral or wild mink & 2020 Aug 28 & C & Negative & ND & ND \\
\hline ID000017 & House mouse & 2020 Aug 25 & C & Negative & 35.89 & Rectal swab \\
\hline ID000064 & Deer mouse & 2020 Aug 30 & B & Negative & $\ddagger$ & Oral swab \\
\hline ID000093 & Deer mouse & 2020 Aug 31 & $\mathrm{~B}$ & Negative & $\ddagger$ & Rectal swab \\
\hline
\end{tabular}

${ }^{*} \mathrm{C}_{\mathrm{t}}$, cycle threshold; rRT-PCR, real-time reverse transcription PCR; SARS-CoV-2, severe acute respiratory syndrome coronavirus 2; ND, not detected. †Mean $\mathrm{C}_{t}$ across the N1- and N2-genes; a positive result is defined as detection of both N1 and N2. $\neq C_{t}$ detection of N1-gene only.

detected by rRT-PCR in 2 samples from deer mice (C 37.55 and 39.57).

Experimental studies of rodents suggest that Old World rodents (e.g., Mus) are resistant to SARS-CoV-2 infection (7) and New World species (e.g., Peromyscus) are susceptible (A. Fagre, unpub. data, https://doi. org/10.1101/2020.08.07.241810; B.D. Griffin, unpub. data, https://doi.org/10.1101/2020.07.25.221291). Given the demonstrated resistance of house mice to SARS-CoV-2 infection, the high- $C_{t}$ rectal swab specimen, in absence of other positive results, suggests potential ingestion and excretion of contaminated material (e.g., food, carcasses) rather than infection. In contrast, the antibody responses of all escaped mink combined with high- $\mathrm{C}_{t}$ swab specimens for some animals suggests recent SARS-CoV-2 infections. These exposures in escaped mink are unsurprising given biosecurity practices on some premises did not exclude incursions of escaped mink into barns.

Although we did not find evidence for SARS-CoV-2 establishment in wildlife, the discovery of escaped mink with the opportunity to disperse and interact with susceptible wildlife, such as wild mink or deer mice, is concerning. In Utah, mink farms often overlap with designated critical mink habitats. Interactions or shared resources between escaped mink and wild mink or other wildlife species represent potential transmission pathways for spillover of SARS-CoV-2 into wildlife and could lead to health consequences or establishment of new reservoirs in susceptible wildlife ( 8 ; A. Fagre, unpub. data, https://doi.org/10.1101/2020.08.07.241810). Heightened biosecurity and best management practices would help prevent accidental releases of infected animals or spillover of SARS-CoV-2 from susceptible species to native wildlife.

\section{Acknowledgments}

We thank the private landowners who generously provided land access. We also thank the Utah Veterinary Diagnostic Laboratory for significant support by providing expertise, space, and access to their facility and the Viral Special Pathogens Branch of the Centers for Disease Control and Prevention for sampling protocols and expertise. We thank the dedicated and skilled staff at state and federal agency laboratories that contributed to this study. We additionally thank the One Health Federal Interagency COVID-19 Coordination Team for efforts to facilitate this work.

This research was supported by the US Department of Agriculture, Wildlife Services.

Any use of trade, firm, or product names is for descriptive purposes only and does not imply endorsement by the US Government.

\section{About the Author}

Dr. Shriner is a wildlife epidemiologist at the US Department of Agriculture, Animal and Plant Health Inspection Service, Wildlife Services, National Wildlife Research Center. Her primary research interests are wildlife epidemiology and disease ecology.

\section{References}

1. Animal and Plant Health Inspection Service. Cases of SARS-CoV-2 in animals in the United States. 2020 Sep 14 [cited 2020 Sep 19]. https://www.aphis.usda.gov/aphis/ ourfocus/animalhealth/sa_one_health/sars-cov-2-animals-us

2. Cahan E. COVID-19 hits U.S. mink farms after ripping through Europe. Science. 2020 Aug 18 [cited 2020 Jan 8]. https:/ / www.sciencemag.org/news/2020/08/covid-19-hitsus-mink-farms-after-ripping-through-europe 
3. ProMed. Coronavirus disease 2019 update (135): Netherlands (North Brabant) animal, farmed mink. 2020 Apr 27 [cited 2020 Jan 8]. http:/ / www.promedmail.org, archive no. 20200427.7272289.

4. Oreshkova N, Molenaar RJ, Vreman S, Harders F, Oude Munnink BB, Hakze-van der Honing RW, et al. SARS-CoV-2 infection in farmed minks, the Netherlands, April and May 2020. Euro Surveill. 2020;25. https:/ / doi.org/ 10.2807/1560-7917.ES.2020.25.23.2001005

5. Molenaar RJ, Vreman S, Hakze-van der Honing RW, Zwart R, de Rond J, Weesendorp E, et al. Clinical and pathological findings in SARS-CoV-2 disease outbreaks in farmed mink (Neovison vison). Vet Pathol. 2020;57:653-7. https://doi.org/10.1177/0300985820943535

6. McAloose D, Laverack M, Wang L, Killian ML, Caserta LC, Yuan F, et al. From people to Panthera: natural SARS-CoV-2 infection in tigers and lions at the Bronx Zoo. MBio. 2020;11:e02220-20. https:// doi.org/10.1128/mBio.02220-20

7. Bao L, Deng W, Huang B, Gao H, Liu J, Ren L, et al. The pathogenicity of SARS-CoV-2 in hACE2 transgenic mice. Nature. 2020;583:830-3. https:// doi.org/10.1038/ s41586-020-2312-y

8. Olival KJ, Cryan PM, Amman BR, Baric RS, Blehert DS, Brook CE, et al. Possibility for reverse zoonotic transmission of SARS-CoV-2 to free-ranging wildlife: a case study of bats. PLoS Pathog. 2020;16:e1008758. https://doi.org/10.1371/ journal.ppat.1008758

Address for correspondence: Susan A. Shriner, USDA APHIS Wildlife Services National Wildlife Research Center, 4101 LaPorte Ave, Fort Collins, CO, 80521, USA; email: Susan.A.Shriner@usda.gov
Mycobacterium bovis infection in wildlife species occurs worldwide. However, few cases of $M$. bovis infection in captive elephants have been reported. We describe 2 incidental cases of bovine tuberculosis in free-ranging African elephants (Loxodonta africana) from a tuberculosis-endemic national park in South Africa and the epidemiologic implications of these infections.

$\mathrm{T}$ uberculosis (TB), caused by the human pathogen Mycobacterium tuberculosis, is a recognized disease in human-managed and wild Asian elephants (Elephas maximus) and African elephants (Loxodonta africana) (1-3). Previous findings demonstrate the importance of human-elephant interfaces for transmission. However, range countries for African and Asian elephants also have high burdens of bovine TB, caused by M. bovis. The World Organisation for Animal Health (OIE) records cases of bovine TB; in the 49 elephant range countries in Africa and Asia, only Namibia is declared free of M. bovis (4). Therefore, the paucity of cases of $M$. bovis infection in elephants is unexpected. The lack of $M$. bovis cases in elephants may be caused by rare or sporadic exposure, innate resistance of the species, or limited surveillance, especially in environments to which bovine TB is endemic.

Kruger National Park (KNP) in South Africa has recorded $M$. bovis infection in $>20$ wildlife species and is considered a bovine TB-endemic area. Although cases of $M$. bovis infection have been reported in other large herbivores, such as black rhinoceros (Diceros bicornis) and white rhinoceros (Ceratotherium simum) $(5,6)$, only 1 case of $M$. tuberculosis infection has been found in an elephant in KNP (3), despite hundreds of individual animals examined during 1967-1994 when elephants were harvested (7). After the discovery of an M. tuberculosis-infected adult bull elephant in 2016 (3), opportunistic sampling of elephants was implemented by park veterinarians.

In May 2018, a young bull elephant (E1; estimated age 18-20 years) was fatally shot in the southern part of KNP. In addition, a young bull elephant (E2; estimated age 3 years) in KNP was euthanized in October 2019 after being found moribund. Postmortem examination of E1 revealed rare small, consolidated masses in the lung. Elephant 2 had several focal firm masses $\left(1-2 \mathrm{~cm}^{2}\right)$ scattered in the lung containing caseous material and some mineralization. We took representative samples from the peripheral (prescapular, inguinal, popliteal), head (parotid, retropharyngeal), thoracic (tracheobronchial), and abdominal (mesenteric) lymph nodes; lung lesions were also sampled. We froze samples at $-20^{\circ} \mathrm{C}$ and 